\title{
BMJ Open Postpartum haemorrhage and risk of long-term hypertension and cardiovascular disease: an English population-based longitudinal study using linked primary and secondary care databases
}

\author{
William Parry-Smith (1) , ${ }^{1,2}$ Dana Šumilo (D) , ${ }^{3}$ Anuradhaa Subramanian, ${ }^{3}$ \\ Krishna Gokhale, ${ }^{3}$ Kelvin Okoth, ${ }^{3}$ Ioannis Gallos, ${ }^{2}$ Arri Coomarasamy, ${ }^{2}$ \\ Krishnarajah Nirantharakumar ${ }^{3}$
}

To cite: Parry-Smith W, Šumilo D, Subramanian A, et al. Postpartum haemorrhage and risk of long-term hypertension and cardiovascular disease: an English population-based longitudinal study using linked primary and secondary care databases. BMJ Open 2021;11:e041566. doi:10.1136/ bmjopen-2020-041566

- Prepublication history for this paper is available online. To view these files, please visit the journal online (http://dx.doi org/10.1136/bmjopen-2020041566).

Received 11 June 2020 Revised 09 March 2021 Accepted 11 March 2021
Check for updates

(c) Author(s) (or their employer(s)) 2021. Re-use permitted under CC BY-NC. No commercial re-use. See rights and permissions. Published by BMJ.

For numbered affiliations see end of article.

Correspondence to Dr William Parry-Smith; william.parry-smith1@nhs.net

\section{ABSTRACT}

Objective To investigate the long-term risk of developing hypertension and cardiovascular disease (CVD) among those women who suffered a postpartum haemorrhage (PPH) compared with those women who did not.

Design Population-based longitudinal open cohort study.

Setting English primary care (The Health Improvement Network (THIN)) and secondary care (Hospital Episode Statistics (HES)) databases.

Population Women exposed to PPH during the study period matched for age and date of delivery, and unexposed.

Methods We conducted an open cohort study using linked primary care THIN and HES Databases, from 1 January 1997 to 31 January 2018. A total of 42327 women were included: 14109 of them exposed to PPH during the study period and 28218 matched for age and date of delivery, and unexposed to PPH. HRs for cardiovascular outcomes among women who had and did not have PPH were estimated after controlling for covariates using multivariate Cox regression models. Outcome measures Risk of hypertensive disease, ischaemic heart disease, heart failure, stroke or transient ischaemic attack.

Results During a median follow-up of over 4 years, there was no significant difference in the risk of hypertensive disease after adjustment for covariates (adjusted HR (aHR): 1.03 (95\% Cl: 0.87 to 1.22); $\mathrm{p}=0.71$ ). We also did not observe a statistically significant difference in the risk of composite CVD (ischaemic heart disease, heart failure, stroke or transient ischaemic attack) between the exposed and the unexposed cohort (aHR: 0.86 (95\% Cl: 0.52 to 1.43; $\mathrm{p}=0.57$ ).

Conclusion Over a median follow-up of 4 years, we did not observe an association between PPH and hypertension or CVD.
Strengths and limitations of this study

- A strength of this study was the adequate sample size and population-wide coverage.

- A strength of this study was the use of a matched controlled study design.

- The study benefited from adjustment for a wide range of relevant covariates.

- An acknowledged limitation of this study is the median follow-up of 4 years.

- A limitation of this study is identification of postpartum haemorrhage and cardiovascular disease within the database and the potential to miss cases that were not correctly coded.

\section{INTRODUCTION}

The widely used definition of postpartum haemorrhage (PPH) is blood loss in excess of $500 \mathrm{~mL}$ following birth. ${ }^{1}$ In 2017-2018, there were 626203 deliveries in National Health Service (NHS) hospitals in England, of which $19 \%$ were complicated by PPH. ${ }^{2}$ Over 100000 women a year in England suffer a PPH but the long-term health consequences beyond a year of experiencing PPH, aside from future fertility and mental health illness, have not been studied to date in the UK. ${ }^{34}$ The majority of the recognised risk factors for PPH are pregnancy related, such as placental abruption and hypertensive disorders of pregnancy which are also overarching risk factors for later development of cardiovascular disease (CVD). ${ }^{56}$

Disease unmasked in or around pregnancy such as pregnancy-induced hypertension, gestational diabetes mellitus (GDM), preterm labour and diseases of placentation including 
fetal growth restriction and placental abruption have previously been demonstrated to identify women at high risk of long-term cardiovascular risk, as shown in a number of cohorts of women with adverse pregnancy outcomes. $^{7-17}$

Given that hypertensive disorders of pregnancy increase the likelihood of $\mathrm{PPH}$, it is possible that $\mathrm{PPH}$ is also a risk factor for later development of hypertension post partum. Hypertensive disease in pregnancy causes poor placentation; this combined with the higher mean arterial blood pressure could predispose to brisker blood loss after delivery. ${ }^{18}$ The PPH episode might therefore unmask the potential for endothelial or vascular dysfunction that may not have manifested as hypertensive disease in pregnancy, therefore remaining as a latent threat for hypertension and CVD in later life. ${ }^{19}$ The interplay between vascular smooth muscle and vascular endothelium is complex and dysfunction of their relationship is thought to be implicated in first steps of pathogenesis contributing to CVD, peripheral vascular disease, stroke and chronic kidney disease. $^{19}$

The risk of poor cardiovascular health in women who have undergone $\mathrm{PPH}$ is thus a possibility and warrants investigation.

To address the gap in our knowledge of the risks following a PPH, we did a cohort study examining the long-term risk of developing hypertension and CVD among those women who suffered a PPH compared with those women who did not.

\section{METHODS}

\section{Study design and data sources}

This study is a population-based retrospective open cohort study using linked primary care (The Health Improvement Network (THIN)) and secondary care (Hospital Episode Statistics (HES)) databases. THIN is a large population-based database in the UK that contains electronic medical records of over 17 million patients from 787 general practices (163 of them linked to the HES Database). The linkage of databases was performed in order to capture information on exposure (PPH) from HES, the long-term cardiovascular outcomes from THIN and important covariates from both THIN (demographics) and HES (records during hospital admission). THIN and HES Databases, on their own and linked, have been extensively used for epidemiological studies, including longitudinal studies that examine long-term outcomes in women with exposure during pregnancy. ${ }^{20-22}$ Core outcomes sets exist for studies evaluating interventions for prevention and treatment of PPH rather than epidemiological outcomes following PPH and were therefore not used.

\section{Patient and public involvement}

We did not seek patient and public involvement for this study in line with current practice for epidemiology research.

\section{Study population}

Women aged between 16 and 46 years who had a record of delivery in HES (which contains information on admissions to NHS hospitals in England) between 1 January 1990 and 31 January 2018 (index delivery) were eligible to be included. Patients in THIN were considered for data linkage 12 months after registration with their practice and where the practice had been using electronic medical records for a minimum of 12 months and had shown acceptable mortality recording in the previous 12 months or before..$^{20}$ These three criteria ensured data quality and sufficient time for maximum and accurate documentation of all covariates. The THIN-HES data linkage was performed by NHS Digital using patient-sensitive de-anonymised data which were then anonymised and received by our team. Once linked, women with a HES record of PPH associated with the index delivery were identified to form the exposed cohort. For each woman exposed to $\mathrm{PPH}$, we randomly selected two controls matched for date of birth ( \pm 1 year) and delivery date ( \pm 1 year). Cohort selection for this study is described in figure 1.

\section{Follow-up period}

Index date was the date of delivery for all women. Patients were followed up using THIN records until the earliest of the following: date they left the general practice, date they died, date the general practice ceased to contribute to the THIN Database, date the outcome of interest was recorded and study end date (31 December 2018).

\section{Exposure definition}

Exposure PPH was defined using International Classification of Diseases, 10th Revision (ICD-10) codes recorded in HES. ICD-10 codes used to identify PPH have previously been used in national audits and other epidemiological studies. ${ }^{23} 24$

\section{Outcomes}

Outcome ascertainment was performed using THIN Read Code records, a hierarchical coding system to document symptoms, signs and diagnosis in primary care. ${ }^{25}$ Hypertension following PPH was the primary outcome of interest. Composite CVD (ischaemic heart disease, stroke or transient ischaemic attack (TIA) and heart failure) and individual components of composite CVD following PPH were secondary outcomes. All outcomes have previously been studied extensively using THIN and are part of the Quality Outcome Framework in the UK, that requires mandatory maintenance of disease registers for these conditions and are thus expected to be documented rigorously. ${ }^{72627}$

\section{Covariates}

Covariates that are independent predictors of outcome other than the exposure of interest were selected on the basis of biological plausibility and previous literature. Information on the following covariates was extracted from THIN: age, body mass index (BMI), socioeconomic status, smoking status, diagnoses of hypertensive disorders 


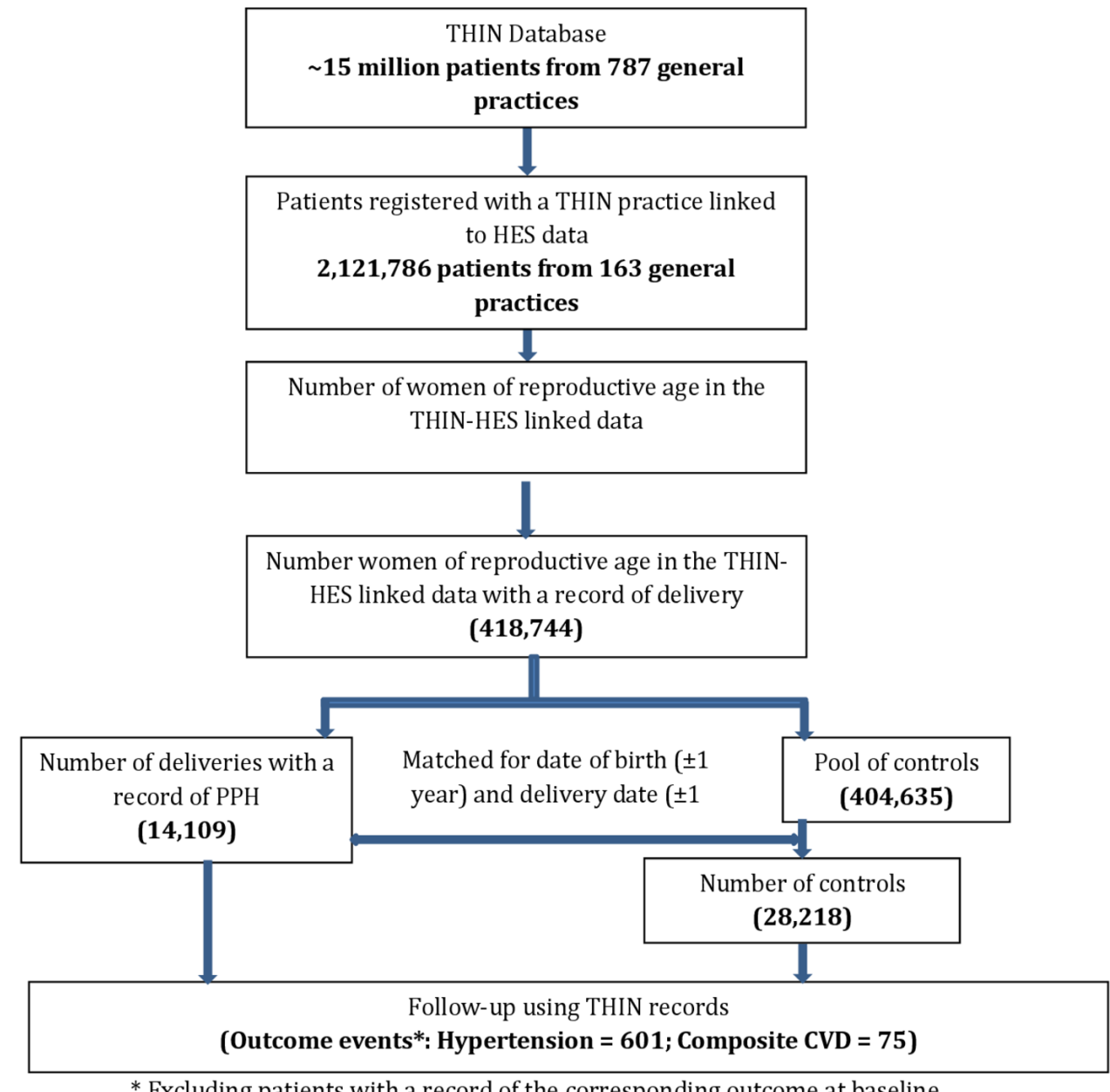

* Excluding patients with a record of the corresponding outcome at baseline.

Figure 1 Cohort selection for the study. CVD, cardiovascular disease; HES, Hospital Episode Statistics; PPH, postpartum haemorrhage; THIN, The Health Improvement Network.

(pre-existing or pregnancy-induced hypertension and pre-eclampsia), gestational diabetes and pre-existing diabetes and prescription records of lipid-lowering drugs.

Age was categorised as 15-19, >20-29, >30-39 and >40 years. BMI was categorised according to the WHO's classification as $<18 \mathrm{~kg} / \mathrm{m}^{2}, 18-24 \mathrm{~kg} / \mathrm{m}^{2},>25-29 \mathrm{~kg} / \mathrm{m}^{2}$ and $>30 \mathrm{~kg} / \mathrm{m}^{2}$. Socioeconomic status in THIN is recorded as Townsend deprivation quintile graded from 1 to 5 with increasing degree of deprivation.

Information on the mode of delivery (spontaneous, caesarean and other delivery methods) was obtained from National Clinical Coding Standards (OPCS) recorded in HES.

Ethnicity data were derived from THIN and, when missing, HES records were used. Missing records of BMI, Townsend score and ethnicity were allocated into the 'missing category' of the corresponding covariate.

\section{Data analysis}

Baseline data stratified by exposure are reported as mean (SD) or median (IQR) for continuous variables depending on the normality of the distribution and as frequency and proportions for categorical variables. Cox regression model was used to obtain crude and adjusted
HRs (aHRs) taking into account the covariates described earlier. All analyses were performed in Stata V.14.0. For each outcome analysis, women with a Read Code recording (in THIN) of the outcome of interest prior to the indexed delivery were excluded.

\section{RESULTS}

A total of 42327 women were included in our study: 14 109 women exposed to PPH during index delivery and 28218 women unexposed to PPH. Baseline summary statistics stratified by the exposure status are provided in table 1. Mean ages at delivery were 30.90 (SD 5.72) and 30.85 (SD 5.68) years for women exposed and unexposed to $\mathrm{PPH}$, respectively. Follow-up period was similar between women exposed and unexposed to PPH (median (IQR) follow-up in years: 4.13 (1.72-7.58) and 4.15 (1.78-7.63), respectively). BMI recorded at baseline was higher among the women exposed to PPH compared with women without PPH (median (IQR): 24.1 (21.5-28.0) and 23.7 (21.2-27.4), respectively). There was no significant difference in socioeconomic status and ethnicity of women with and without PPH. Women who 
Table 1 Baseline characteristics

\begin{tabular}{|c|c|c|}
\hline & $\begin{array}{l}\text { Women with PPH } \\
\text { (exposed) } \\
\text { ( } n=14 \text { 109) }\end{array}$ & $\begin{array}{l}\text { Women without } \\
\text { PPH (unexposed) } \\
\text { ( } n=28 \text { 218) }\end{array}$ \\
\hline Age (mean (SD)) & $30.90(5.72)$ & 30.85 (5.68) \\
\hline $\begin{array}{l}\text { BMI }\left(\mathrm{kg} / \mathrm{m}^{2}\right) \text { (median } \\
(\mathrm{IQR}))\end{array}$ & $24.1(21.5-28.0)$ & $23.7(21.2-27.4)$ \\
\hline \multicolumn{3}{|l|}{$\begin{array}{l}\text { BMI categories ( } \mathrm{n} \\
(\%))\end{array}$} \\
\hline$<18 \mathrm{~kg} / \mathrm{m}^{2}$ & 239 (1.69) & $635(2.25)$ \\
\hline $\begin{array}{l}18-24 \mathrm{~kg} / \mathrm{m}^{2} \\
\text { (reference) }\end{array}$ & 6742 (47.79) & 14015 (49.67) \\
\hline $25-29 \mathrm{~kg} / \mathrm{m}^{2}$ & 3100 (21.97) & $5711(20.24)$ \\
\hline$\geq 30 \mathrm{~kg} / \mathrm{m}^{2}$ & 2164 (15.34) & 3717 (13.17) \\
\hline Missing & $1864(13.21)$ & 4140 (14.67) \\
\hline \multicolumn{3}{|l|}{$\begin{array}{l}\text { Townsend deprivation } \\
\text { quintile ( } \mathrm{n}(\%) \text { ) }\end{array}$} \\
\hline 1 (reference) & 3341 (23.68) & 6316 (22.38) \\
\hline 2 & 2573 (18.24) & 5035 (17.84) \\
\hline 3 & 3087 (21.88) & 6216 (22.03) \\
\hline 4 & 2741 (19.43) & 5582 (19.78) \\
\hline 5 & 1567 (11.11) & 3349 (11.87) \\
\hline Missing & $800(5.67)$ & $1720(6.10)$ \\
\hline
\end{tabular}

Smoking status ( $\mathrm{n}$

(\%))

\begin{tabular}{|c|c|c|}
\hline $\begin{array}{l}\text { Non-smoker } \\
\text { (reference) }\end{array}$ & $8473(60.05)$ & $16060(56.91)$ \\
\hline Ex-smoker & $2887(20.46)$ & 5552 (19.68) \\
\hline Smoker & 2409 (17.07) & 5906 (20.93) \\
\hline Missing & $340(2.41)$ & 700 (2.48) \\
\hline \multicolumn{3}{|l|}{$\begin{array}{l}\text { Baseline } \\
\text { comorbidities (n (\%)) }\end{array}$} \\
\hline $\begin{array}{l}\text { Hypertensive } \\
\text { disorders (pre- } \\
\text { eclampsia, } \\
\text { pregnancy-induced } \\
\text { and pre-existing } \\
\text { hypertension) }\end{array}$ & $298(2.11)$ & $518(1.84)$ \\
\hline $\begin{array}{l}\text { Hypertensive } \\
\text { disorders of } \\
\text { pregnancy } \\
\text { (pregnancy- } \\
\text { induced } \\
\text { hypertension and } \\
\text { pre-eclampsia) }\end{array}$ & $128(0.91)$ & $227(0.80)$ \\
\hline $\begin{array}{l}\text { Pre-existing } \\
\text { hypertension }\end{array}$ & $186(1.32)$ & 306 (1.08) \\
\hline $\begin{array}{l}\text { Gestational } \\
\text { diabetes }\end{array}$ & 352 (2.49) & $598(2.12)$ \\
\hline $\begin{array}{l}\text { Pre-existing } \\
\text { diabetes }\end{array}$ & $120(0.85)$ & $200(0.71)$ \\
\hline $\begin{array}{l}\text { Combined } \\
\text { cardiovascular } \\
\text { disease }\end{array}$ & $22(0.16)$ & $44(0.16)$ \\
\hline $\begin{array}{l}\text { Ischaemic heart } \\
\text { disease }\end{array}$ & $3(0.02)$ & $7(0.02)$ \\
\hline Heart failure & $0(0.00)$ & $2(0.01)$ \\
\hline
\end{tabular}

Continued
Table 1 Continued

\begin{tabular}{|c|c|c|}
\hline & $\begin{array}{l}\text { Women with PPH } \\
\text { (exposed) } \\
(\mathrm{n}=14 \text { 109) }\end{array}$ & $\begin{array}{l}\text { Women without } \\
\text { PPH (unexposed) } \\
\text { (n=28 218) }\end{array}$ \\
\hline Stroke/TIA & $19(0.13)$ & $39(0.14)$ \\
\hline \multicolumn{3}{|l|}{$\begin{array}{l}\text { Baseline drug } \\
\text { prescription (n (\%)) }\end{array}$} \\
\hline $\begin{array}{l}\text { Lipid-lowering } \\
\text { drugs }\end{array}$ & $51(0.36)$ & $115(0.41)$ \\
\hline \multicolumn{3}{|l|}{$\begin{array}{l}\text { Mode of delivery ( } \mathrm{n} \\
(\%) \text { ) }\end{array}$} \\
\hline $\begin{array}{l}\text { Spontaneous } \\
\text { (reference) }\end{array}$ & $5576(39.52)$ & $16422(58.20)$ \\
\hline Caesarean & $5173(36.66)$ & $7020(24.88)$ \\
\hline $\begin{array}{l}\text { Other delivery } \\
\text { methods }\end{array}$ & $3360(23.81)$ & 4776 (16.93) \\
\hline \multicolumn{3}{|l|}{ Ethnicity (n (\%)) } \\
\hline $\begin{array}{l}\text { Caucasians } \\
\text { (reference) }\end{array}$ & $10949(77.60)$ & 22023 (78.05) \\
\hline South Asians & 695 (4.93) & $1340(4.75)$ \\
\hline Afro-Caribbeans & $502(3.56)$ & $894(3.17)$ \\
\hline Mixed race & $193(1.37)$ & $373(1.32)$ \\
\hline Other race & $490(3.47)$ & 953 (3.38) \\
\hline Missing & $1280(9.07)$ & 2635 (9.34) \\
\hline
\end{tabular}

BMI, body mass index; PPH, postpartum haemorrhage; TIA, transient ischaemic attack.

experienced PPH were less likely to be smokers compared with women who did not experience PPH during delivery (2409 (17.07\%) vs $5906(20.93 \%))$. Proportion of women with a record of pre-existing hypertension and diabetes and proportion prescribed with lipid-lowering drugs were similar between the two groups. However, there was a slightly higher proportion of women with GDM among the exposed compared with the unexposed (352 (2.49\%) vs $597(2.12 \%)$, respectively). There were also differences in the delivery methods between the two groups; higher proportion of women with PPH underwent caesarean section (5173 (36.66\%) vs $7020(24.88 \%))$ and other non-spontaneous delivery methods (5576 (39.52\%) vs 16 $422(58.20 \%))$.

\section{Risk of hypertension}

A total of $218(1.6 \%)$ women exposed to PPH and 383 (1.4\%) women unexposed to PPH developed hypertension during follow-up, with an incidence rate of 3.12 and 2.72 per 1000 person-years. There was no significant difference in the risk of hypertension between women who were exposed and unexposed to PPH (HR: 1.14 (95\% CI: 0.97 to $1.35, \mathrm{p}=0.118$ ), including after adjustment for covariates (aHR: 1.03 (95\% CI: 0.87 to 1.22); $\mathrm{p}=0.710)$ (see table 2).

\section{Risk of CVD}

Twenty-three $(0.16 \%)$ women exposed to PPH and 52 $(0.18 \%)$ women unexposed to PPH developed at least 
Table 2 Crude and adjusted HR rate for hypertension and cardiovascular disease (CVD) among women who were exposed to $\mathrm{PPH}$ compared with women unexposed to PPH

\begin{tabular}{|c|c|c|c|}
\hline & & Exposed to PPH & Unexposed to PPH \\
\hline \multirow[t]{4}{*}{ Hypertension } & Total $\mathbf{n}$ & 13923 & 27912 \\
\hline & Outcomes, n (\%) & $218(1.57)$ & $383(1.37)$ \\
\hline & HR rate $(95 \% \mathrm{Cl}) ; \mathrm{p}$ value & 1.14 (0.97 to 1.35$) ; 0.118$ & \\
\hline & Adjusted HR rate $(95 \% \mathrm{Cl}) ; \mathrm{p}$ value ${ }^{*}$ & 1.03 (0.87 to 1.22$) ; 0.710$ & \\
\hline \multirow{4}{*}{$\begin{array}{l}\text { Composite CVD (ischaemic } \\
\text { heart disease, heart failure, } \\
\text { stroke/transient ischaemic } \\
\text { attack) }\end{array}$} & Outcomes, n (\%) & $23(0.16)$ & $52(0.18)$ \\
\hline & Follow-up (person-years) & 71666 & 143724 \\
\hline & HR rate $(95 \% \mathrm{Cl}) ; \mathrm{p}$ value & 0.88 (0.54 to 1.44$) ; 0.621$ & \\
\hline & Adjusted HR rate $(95 \% \mathrm{Cl}) ; \mathrm{p}$ value $\dagger$ & 0.86 (0.52 to 1.43$) ; 0.572$ & \\
\hline
\end{tabular}

*Adjusted for age category, BMI category, smoking status, ethnicity, Townsend deprivation quintile, baseline record of hypertensive disorders of pregnancy (pregnancy-induced hypertension and pre-eclampsia), gestational diabetes, pre-existing diabetes, baseline prescription of lipidlowering drugs and delivery method.

†Adjusted for age category, BMI category, smoking status, ethnicity, Townsend deprivation quintile, baseline record of hypertensive disorders (pre-existing/pregnancy-induced hypertension and pre-eclampsia), gestational diabetes, pre-existing diabetes, baseline prescription of lipidlowering drugs and delivery method.

$\mathrm{BMI}$, body mass index; PPH, postpartum haemorrhage.

one of the three components of the composite cardiovascular outcome during follow-up. After adjustment for covariates, there was no significant difference in the risk of composite CVD between the exposed and the unexposed cohort (aHR: 0.86 (95\% CI: 0.52 to 1.43 ; $\mathrm{p}=0.572$ ) (see table 2). When the individual components of the CVD were analysed as outcomes, none of these individual outcomes were significantly different between the exposed and the unexposed cohort (aHR-ischaemic heart disease: 1.00 (95\% CI: 0.30 to 3.32 ); $\mathrm{p}=0.995$, heart failure: 0.76 (95\% CI: 0.25 to 2.31 ); $\mathrm{p}=0.634$, and stroke or TIA: 0.79 (95\% CI: 0.43 to 1.47 ); $\mathrm{p}=0.461$ ) (see figure 2 ).

\section{DISCUSSION}

To our knowledge, this is the first English population-wide longitudinal study to date investigating cardiovascular risk following PPH and includes over 14000 episodes of PPH and over 210000 person-years of follow-up. Women who experienced $\mathrm{PPH}$ were found not to be at increased risk of developing hypertension nor composite CVD (heart

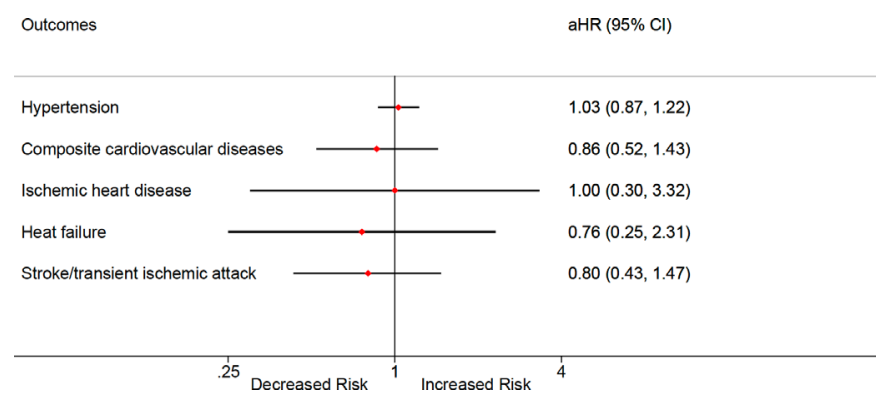

Figure 2 Adjusted HRs (aHRs) for different cardiovascular outcomes following exposure to postpartum haemorrhage. failure, stroke or TIA and ischaemic heart disease) when compared with women who did not experience PPH.

The hypothesis that having PPH might unmask a latent risk of developing future CVD is, as discussed in the introduction, plausible though not supported in the follow-up period of this study. PPH is thought to occur more frequently in those women with pre-existing congenital heart disease. ${ }^{28}$ In episodes of severe PPH requiring admission to intensive care, myocardial ischaemiainduced injury was associated with severe PPH, though there was no long-term follow-up of these women. ${ }^{29}$ It has been speculated that the marked physiological response caused by a PPH might cause vulnerable arteriosclerotic plaque changes and precipitate coronary disease and myocardial infarction in the short term. ${ }^{30}$

CVD is a leading cause of death among women, and when combined with the high prevalence of $\mathrm{PPH}$ following childbirth, an association could have been of importance at individual and population levels. Our study provides reassurance for women who have had a PPH with regard to future cardiovascular risk up to 4 years following delivery. ${ }^{31}$

\section{Strengths and weaknesses}

This study has several strengths including its sample size, population-wide coverage, and controlling for confounding by using the matched controlled study design and adjusting for a wide range of relevant covariates. The finding that smoking is protective for $\mathrm{PPH}$ is in keeping with previous research and may be due to increased risk of poor uteroplacental blood flow in the smoking population and/or the hypercoagulation effects of smoking. ${ }^{32} 33$ 
Measurement of blood loss and definition of PPH, however, are a challenge with recognised underestimation of blood loss. We were only able to identify women who had PPH and CVD if it was coded in the database.

A previous study identified increased cardiovascular risk following maternal placental syndromes at between 3 and 5 years following delivery. ${ }^{31}$ The follow-up period in our study was similar between women exposed and unexposed to PPH but the follow-up time frame could have been too short to observe an effect as relatively few women had a diagnosis of CVD. However, it is reassuring that the risk of cardiovascular events is highest immediately following delivery and decline over time. ${ }^{34}$

A recent well-conducted Canadian study reported that $\mathrm{PPH}$ was not associated with an increase in cardiovascular risk aHR of 1.02 (95\% CI: 0.97 to 1.07), in line with the results of our study. ${ }^{34}$ A recent Korean study also supports the findings of our study in that there was no difference in the risk of CVD in women with PPH or without PPH after adjustment (HR: $0.96,95 \%$ CI: 0.86 to 1.07 ), which is broadly comparable with our study (aHR: 0.86 (95\% CI: 0.52 to $1.43 ; \mathrm{p}=0.57) .{ }^{35}$ However, when Cho $e$ t $a l^{35}$ examined only those women who had a PPH requiring a blood transfusion, the risk of CVD was significantly increased after adjustment (HR: $1.60,95 \%$ CI: 1.25 to 2.06 ). We were unable to stratify our results by blood transfusion, which would have proven a useful approach.

\section{Implications for clinical practice}

Long-term morbidity and disease as a consequence of PPH deserves vigilance but there is no particular cause for concern regarding an increase in cardiovascular risk in this patient group. The long-term effects of PPH are little studied, the use of public/national data sets should increase the literature to address important public health questions.

\section{CONCLUSION}

Over a median follow-up of 4 years, we did not observe an association between PPH and hypertension or CVD.

\section{Author affiliations}

${ }^{1}$ Department of Obstetrics and Gynaecology, Shrewsbury and Telford Hospital NHS Trust, Telford, UK

${ }^{2}$ Institute of Metabolism and Systems Research, University of Birmingham, Birmingham, UK

${ }^{3}$ Institute of Applied Health Research, University of Birmingham, Birmingham, UK

\section{Twitter William Parry-Smith @wparrysmith}

Acknowledgements IQVIA Medical Research Data (IMRD) incorporates data from THIN, A Cegedim Database. Reference made to THIN is intended to be descriptive of the data asset licensed by IQVIA. This work used de-identified data provided by patients as a part of their routine care.

Contributors WPS, DS and KN conceived the idea for the study. WPS wrote the manuscript. WPS, DS, KN, AS, KO and KG made substantial contributions to the design, acquisition of data, or analysis and interpretation of data. WPS, DS, KN, AS, $\mathrm{KO}, \mathrm{KG}$, IG and AC drafted the article or revised it critically for important intellectual content. All authors approved the final version of the manuscript to be published. $\mathrm{KN}$ is the guarantor of this work.
Funding The authors have not declared a specific grant for this research from any funding agency in the public, commercial or not-for-profit sectors.

Competing interests None declared.

Patient and public involvement Patients and/or the public were not involved in the design, or conduct, or reporting, or dissemination plans of this research.

Patient consent for publication Not required.

Ethics approval The NHS South-East Multi-Centre Research Ethics Committee approved undertaking research using anonymised THIN data, provided an independent scientific review is undertaken. The study protocol (18THIN035) was reviewed and approved by the IQVIA Scientific Review Committee (SRC) and Independent Scientific Ethical Advisory Committee (ISEAC).

Provenance and peer review Not commissioned; externally peer reviewed.

Data availability statement THIN data governance does not allow us to share individual patient data. Researchers may apply for individual patient data access at $\mathrm{https}$ ://iqvia.com/solutions/real-world-value-and-outcomes.

Open access This is an open access article distributed in accordance with the Creative Commons Attribution Non Commercial (CC BY-NC 4.0) license, which permits others to distribute, remix, adapt, build upon this work non-commercially, and license their derivative works on different terms, provided the original work is properly cited, appropriate credit is given, any changes made indicated, and the use is non-commercial. See: $\mathrm{http} / / / \mathrm{creativecommons.org/licenses/by-nc/4.0/.}$

\section{ORCID iDs}

William Parry-Smith http://orcid.org/0000-0002-0017-7266

Dana Šumilo http://orcid.org/0000-0001-6732-2459

\section{REFERENCES}

1 WHO. WHO recommendations for the prevention and treatment of postpartum haemorrhage [Internet]. World Health Organization. 2012. 1-41 p. Available from. Available: www.who.int/maternal_child adolescent\%5Cnhttp://www.who.int/reproductivehealth/publications/ maternal_perinatal_health/9789241548502/en/

2 NHS Maternity Statistics [Internet], 2018. Available: https://files. digital.nhs.uk/C3/47466E/hosp-epis-stat-mat-summary-report 201718.pdf [Accessed cited 2019 Oct 7].

3 Gizzo S, Saccardi C, Patrelli TS, et al. Fertility rate and subsequent pregnancy outcomes after conservative surgical techniques in postpartum hemorrhage: 15 years of literature. Fertil Steril 2013;99:2097-107 http://linkinghub.elsevier.com/retrieve/pii/ S0015028213002707

4 Ricbourg A, Gosme C, Gayat E, et al. Emotional impact of severe post-partum haemorrhage on women and their partners: an observational, case-matched, prospective, single-centre pilot study. Eur J Obstet Gynecol Reprod Biol 2015;193:140-3 http://linkinghub. elsevier.com/retrieve/pii/S0301211515002572

5 Garovic V, August P. Preeclampsia and the future risk of hypertension: the Pregnanct evidence. Curr Hypertens Rep 2014;15:1-14.

6 Oliver-Williams C, Lo C, Lo A. 108 future cardiovascular disease risk for women with a history of gestational hypertension: a systematic review and meta-analysis. Heart [Internet] 2019;105:A89 https:// heart.bmj.com/content/105/Suppl_6/A89.1

7 Daly B, Toulis KA, Thomas N, et al. Increased risk of ischemic heart disease, hypertension, and type 2 diabetes in women with previous gestational diabetes mellitus, a target group in general practice for preventive interventions: a population-based cohort study. PLoS Med 2018;15:e1002488 http://www.ncbi.nlm.nih.gov/pubmed/ 29337985

8 Ray JG, Vermeulen MJ, Schull MJ, et al. Cardiovascular health after maternal placental syndromes (CHAMPS): population-based retrospective cohort study. Lancet 2005;366:1797-803 https://www. sciencedirect.com/science/article/pii/S0140673605677264?via\% 3Dihub

9 Kramer CK, Campbell S, Retnakaran R. Gestational diabetes and the risk of cardiovascular disease in women: a systematic review and meta-analysis. Diabetologia [Internet] 2019;62:905-14 http://link. springer.com/

10 Brown MC, Best KE, Pearce MS, et al. Cardiovascular disease risk in women with pre-eclampsia: systematic review and meta-analysis author. Source Eur J Epidemiol [Internet] 2013;28:1-19 https://www. jstor.org/stable/23458525?seq=1\&cid=pdf-reference\#references tab_contents 
11 McDonald SD, Malinowski A, Zhou Q, et al. Cardiovascular sequelae of preeclampsia/eclampsia: a systematic review and meta-analyses. Am Heart J 2008;156:918-30 https://www.sciencedirect.com/ science/article/abs/pii/S0002870308006248?via\%3Dihub

12 Bellamy L, Casas J-P, Hingorani AD, et al. Pre-Eclampsia and risk of cardiovascular disease and cancer in later life: systematic review and meta-analysis. BMJ 2007;335:974 http://www.ncbi.nlm.nih.gov/ pubmed/17975258

13 Wu P, Haththotuwa R, Kwok CS, et al. Preeclampsia and future cardiovascular health. Circ Cardiovasc Qual Outcomes [Internet] 2017;10 http://www.ncbi.nlm.nih.gov/pubmed/28228456

14 Wu P, Gulati M, Kwok CS, et al. Preterm delivery and future risk of maternal cardiovascular disease: a systematic review and MetaAnalysis. J Am Heart Assoc 2018;7.

15 Brouwers L, van der Meiden-van Roest AJ, Savelkoul C, et al. Recurrence of pre-eclampsia and the risk of future hypertension and cardiovascular disease: a systematic review and meta-analysis. BJOG 2018;125:1642-54 http://doi.wiley.com/

16 Hopmans T-EJP, van Houten CB, Kasius A, et al. [Increased risk of type II diabetes mellitus and cardiovascular disease after gestational diabetes mellitus: a systematic review]. Ned Tijdschr Geneeskd [Internet] 2015;159:A8043.

17 Li J, Song C, Li C, et al. Increased risk of cardiovascular disease in women with prior gestational diabetes: a systematic review and meta-analysis. Diabetes Res Clin Pract [Internet] 2018;140:324-38 http://www.ncbi.nlm.nih.gov/pubmed/29655653

18 Magnussen EB, Vatten LJ, Smith GD. På. hypertensive disorders in pregnancy and subsequently measured cardiovascular risk factors. Obstet \&amp [Internet] 2009;114:961-70 https://insights.ovid.com/ pubmed?pmid=20168095

19 Rajendran P, Rengarajan T, Thangavel J, et al. The vascular endothelium and human diseases. Int J Biol Sci [Internet]. 2013;9:1057-69 http://www.ncbi.nlm.nih.gov/pubmed/24250251

20 Lavrentaki A, Thomas T, Subramanian A, et al. Increased risk of non-alcoholic fatty liver disease in women with gestational diabetes mellitus: a population-based cohort study, systematic review and meta-analysis. J Diabetes Complications [Internet] 2019;33:107401 http://www.ncbi.nlm.nih.gov/pubmed/31326267

21 Achana FA, Fleming KM, Tata LJ, et al. Peripartum hysterectomy: an economic analysis of direct healthcare costs using routinely collected data. BJOG: Int J Obstet Gy 2018;125:874-83.

22 Abdul Sultan A, West J, Tata LJ, et al. Risk of first venous thromboembolism in pregnant women in hospital: population based cohort study from England. BMJ [Internet] 2013;347:f6099 http:// www.scopus.com/inward/record.url?eid=2-s2.0-84888159987\& partnerID=tZOtx3y1
23 Nair M, Kurinczuk JJ, Knight M. Establishing a national maternal morbidity outcome indicator in England: a population-based study using routine hospital data. Ciccozzi M, editor. PLoS One [Internet] 2016;11:e0153370 http://dx.plos.org/

24 National Maternity and Perinatal Audit [Internet]. Available: http:// www.maternityaudit.org.uk/Audit/Charting/Clinical [Accessed cited 2019 Oct 9].

25 BOOTH N. What are the read codes? Health Libr Rev [Internet] 1994;11:177-82.

26 Adderley NJ, Subramanian A, Nirantharakumar K, et al. Association between idiopathic intracranial hypertension and risk of cardiovascular diseases in women in the United Kingdom. JAMA Neurol 2019;76:1088.

27 Tracy A, Subramanian A, Adderley NJ, et al. Cardiovascular, thromboembolic and renal outcomes in IgA vasculitis (HenochSchönlein purpura): a retrospective cohort study using routinely collected primary care data. Ann Rheum Dis 2019;78:261-9.

28 Cauldwell M, Von Klemperer K, Uebing A, et al. Why is post-partum haemorrhage more common in women with congenital heart disease? Int J Cardiol 2016;218:285-90.

29 Karpati P, Rossignol M, Pirot M. Anesthesiology. J Am Soc Anesthesiol [Internet] 2004;100:30-6.

30 Chou M-H, Chen Y-C, Hwang K-S, et al. Myocardial infarction and ischemic hepatitis complicated by postpartum hemorrhage. Taiwan $J$ Obstet Gynecol 2016;55:437-40.

31 Cain MA, Salemi JL, Tanner JP, et al. Pregnancy as a window to future health: maternal placental syndromes and short-term cardiovascular outcomes. Am J Obstet Gynecol 2016;215:484. e1-484.e14.

32 Briley A, Seed PT, Tydeman G, et al. Reporting errors, incidence and risk factors for postpartum haemorrhage and progression to severe PPH: a prospective observational study. BJOG An Int J Obstet Gynaecol 2014;121:876-88.

33 Nielsen VG, Hafner DT, Steinbrenner EB. Tobacco smoke-induced hypercoagulation in human plasma. Blood Coagul Fibrinolysis [Internet] 2013;24:405-10 http://www.ncbi.nlm.nih.gov/pubmed/ 23429254

34 Ukah UV, Platt RW, Dayan N. Obstetric hemorrhage and risk of cardiovascular disease after three decades: a population-based cohort study. BJOG An Int J Obstet Gynaecol 2020:0-2.

35 Cho GJ, Lee KM, Kim HY, et al. Postpartum haemorrhage requiring transfusion and risk of cardiovascular disease later in life: a retrospective cohort study. BJOG An Int J Obstet Gynaecol 2020:738-44. 